\title{
Profile of DNA damage protective effect and antioxidant activity of different solvent extracts from the pericarp of Garcinia mangostana
}

\author{
Wei Qin Li, Jian Guo Xu* \\ College of Food Sciences, Shanxi Normal University, Linfen, China \\ Email address: \\ Liuyu1961119@163.com (Wei Qin Li),xjg71@163.com (Jian Guo Xu)
}

To cite this article:

Wei Qin Li, Jian Guo Xu. Profile of DNA Damage Protective Effect and Antioxidant Activity of Different Solvent Extracts from the Pericarp of Garcinia Mangostana. Journal of Food and Nutrition Sciences. Special Issue: Emerging Issues in Food Safety, Food Additives: Risk Assessment, Analytical Methods and Replacement in Foodstuffs. Vol. 3, No. 1-1, 2015, pp. 1-6.

doi: $10.11648 /$ j.jfns.s.2015030101.11

\begin{abstract}
The content of total polyphenols, DNA damage protective effect, and antioxidant activity of different solvent extracts including hexane, acetidin (ethyl acetate), acetone, ethanol, and methanol) from Garcinia mangostana pericarp were investigated and compared. The results showed that the content of total polyphenols is significantly affected by extracting solvents, and resulting in variation of antioxidant activities of Garcinia mangostana pericarp. Methanol, acetone, and ethanol extracts exhibited the better DNA protective effect, the same as that of $100 \mu \mathrm{M}$ of Trolox. The methanol extract exhibited the strongest antioxidant activities because it possessed the highest total polyphenols content, followed by acetone and ethanol extracts, while other extracts had both lower the content of active compounds and bioactivities. These results indicated that selective extraction from Garcinia mangostana pericarp, by an appropriate solvent, is important for obtaining fractions with high antioxidant activity, which will be useful for the developing and application of mangosteen pericarp as a new local source of bioactive compounds in foods and medicine industries.
\end{abstract}

Keywords: Garcinia Mangostana Pericarp, Extracts, DNA, Antioxidant Activity

\section{Introduction}

Reactive oxygen species (ROS) and reactive nitrogen species (RNS) are products of normal cellular metabolism in living organisms [1]. However, the excessive amounts of ROS and RNS bring about degradation of cellular components such as carbohydrates, proteins, lipids, DNA and RNA, which lead to cell death and tissue damage. So many pathophysiological conditions are initiated by excess reactive species [2-4]. In addition, ROS is also one of the major causes of spoilage of foods containing significant amounts of polyunsaturated fatty acids [3-5]. In industry, synthetic chemicals have frequently been made to prevent oxidation. However, consumers have grown concerned about the side effects of synthetic chemicals and want safe materials for preventing and controlling the oxidation in foods $[6,7]$.

Plants can be an excellent source of natural antioxidants and can be effectively used in the food industry as a source of dietary supplements or as natural antioxidants to preserve the quality and improve the shelf-life of food products $[6,8]$. The plants or their extracts can also be used as natural colorants of foodstuffs, and they are believed to be safe, and non-toxic to humans $[9,10]$. Of late, many compounds, especially of plant origin, have been reported to exhibit rich antioxidant properties [6,7].

The mangosteen (Garcinia mangostana L.), belonging to the family Guttiferae, is a tropical evergreen tree widely distributed in India, Myanmar, Malaysia, Philippines, Sri Lanka, and Thailand [11]. The mangosteen-fruit is dark purple or reddish, with white, soft and juicy edible pulp with a slightly acid and sweet flavor and a pleasant aroma [12], and its products are now widely available and are highly popular because of their perceived role in enhancing human health. The pericarp of mangosteen fruit has also been used as a medicinal agent by Southeast Asians for centuries in the treatment of abdominal pain, dysentery, suppuration, infected wound, leucorrhoea, chronic ulcer, cholera and fever $[11,13,14]$. It contains abundant bioactive substances such as mangostin, tannin, xanthone, flavone, phenolic 
compounds and so on [15-17], which can make it possess a wide range of biological activities, such as antioxidant activity [18, 19], antibacterial activity [20, 21], anti-inflammatory activity [22], antitumor activity [23], cytotoxic activities [13] and so on [11, 24]. However, the content of bioactive substances is affected by genetic, cultural practices and climatic factors during the plant growth cycle. The extraction yield is influenced by extraction methods $[25,26]$ and extraction solvents $[27,28]$ during extraction due to differences in the structure of these compounds and their physicochemical properties. So depending on the solvent used for extracting bioactive compounds, extracts obtained from the same plant may vary widely with respect to their concentration and activities [27, 28]. To the best of our knowledge, data on the pericarp of Garcinia mangostana in this respect are still scarce. In order to assess the effect of solvent system on the content and antioxidant activities of bioactive substances from mangosteen pericarp, we compared the content of total phenolics, and their DNA damage protective effect, and antioxidant activities of mangosteen pericarp under five extracting solvents. The expected results will be useful for the developing and application of mangosteen pericarp as a new local source of bioactive compounds for economic and health utilization.

\section{Materials and Methods}

\subsection{Plant Materials}

The Garcinia mangostana fruit at the commercially mature stage was bought in the summer of 2013 from a local supermarket. The plant material was identified by Prof. Qing-Ping Hu, College of Life Sciences, Shanxi Normal University. A voucher specimen was deposited in the College of Life Sciences, Shanxi Normal University, Linfen City, China. They were cleaned with distilled water and then peeled manually. Subsequently, the fruit pericarp was lyophilized and then stored in polyethylene bags at 4 ${ }^{\circ} \mathrm{C} \pm 0.5^{\circ} \mathrm{C}$ until analysis.

\subsection{Reagents}

2,4,6-Tri-(2-pyridyl)-s-triazine (TPTZ) and Trolox were purchased from Fluka (Switzerland). Gallic acid, agarose, 2,2'-azino-bis (3-ethylbenothiazoline-6-sulfonic acid) diammonium salts (ABTS), ethidium bromide, and 2,2-Diphenyl-1-picrylhydrazyl (DPPH) were purchased from Sigma (United States). Plasmid DNA was purchased from Bao Bioengineering Co. LTD. Other chemicals used were all of analytical grade.

\subsection{Preparation of Extracts}

The dried fruit pericarps were finely ground by a micro plant grinding machine (FZ102; Tianjin Taisite Instruments, Tianjin, China). Ground samples (500 g) were blended with $5 \mathrm{~L}$ solvent and shaken with a laboratory rotary shaker at 150 rpm for $4 \mathrm{~h}$ at $30{ }^{\circ} \mathrm{C}$, and then the homogenates were centrifuged for $20 \mathrm{~min}$ at $4{ }^{\circ} \mathrm{C}$ and $5000 \mathrm{~g}$ in a centrifuge (Eppendorf 5417R, Germany). After centrifugation, the supernatants were pooled, and vacuum-evaporated to dryness at $40{ }^{\circ} \mathrm{C}$. Extracts were obtained using different solvents with increasing polarity: hexane, acetidin, acetone, ethanol, and methanol. All extracts were stored at $-4{ }^{\circ} \mathrm{C}$ until analysis was performed.

\subsection{Determination of Total Phenolic Content (TPC)}

Total phenolic content was determined as described by Rebey et al. [29] with slight modifications. An aliquot (0.1 $\mathrm{mL}$ ) of diluted extracts, $2.8 \mathrm{~mL}$ of deionized water and 0.1 $\mathrm{mL}$ of $1.0 \mathrm{M}$ Folin-Ciocalteu reagent were mixed and stirred. After $8 \mathrm{~min}, 2 \mathrm{~mL}$ of $7.5 \%$ sodium carbonate solution was added and mixed thoroughly. The absorbance of the reaction mixtures was measured at $765 \mathrm{~nm}$ after incubation for $2 \mathrm{~h}$ at room temperature. Gallic acid was used for calibration of the standard curve and total phenolic content was expressed as milligram gallic acid equivalent per gram dried weight (mg GAE/g DW). All extracts were tested in triplicates.

\subsection{Antioxidant Activities}

\subsubsection{DPPH Assay}

The DPPH radical scavenging activity was determined according to the method of $\mathrm{Xu}, \mathrm{Hu}$, and Liu [30]. Briefly, each of sample solution was serially diluted in methanol to various concentrations respectively, and then $0.5 \mathrm{~mL}$ of samples was mixed with $2.5 \mathrm{~mL}$ of $60 \mu \mathrm{M}$ DPPH dissolved in methanol. The mixture was shaken vigorously and left to stand for $30 \mathrm{~min}$ in the dark, and the absorbance was measured at $517 \mathrm{~nm}$ against a solvent blank. The scavenging rate on DPPH radicals was calculated according to the formula: scavenging rate $(\%)=\left[1-\left(\mathrm{A}_{1}-\mathrm{As}\right) / \mathrm{A}_{0}\right] \times 100$, where $\mathrm{A}_{0}$ is the absorbance of the control solution $(0.5 \mathrm{~mL}$ methanol in $4.5 \mathrm{~mL}$ of DPPH solution), $\mathrm{A}_{1}$ is the absorbance in the presence of phenolic extracts in DPPH solution and As, which is used for error correction arising from unequal color of the sample solutions, is the absorbance of the extracts solution without DPPH. The scavenging activity of the sample on DPPH radicals was expressed by $\mathrm{EC}_{50}$ value. All extracts were tested in triplicates. $\mathrm{EC}_{50}$ value is the effective concentration at which DPPH radicals are scavenged by $50 \%$ and is obtained by interpolation from regression analysis. A lower $\mathrm{EC}_{50}$ value corresponds to a higher scavenging capacity.

\subsubsection{ABTS Assay}

The ABTS cation radical scavenging activity was determined according to the method described by $\mathrm{Xu}, \mathrm{Hu}$, and Liu [30]. Briefly, ABTS cation radicals were generated by a reaction of $7.0 \mathrm{mmol} / \mathrm{L}$ ABTS and $2.45 \mathrm{mmol} / \mathrm{L}$ potassium persulfate. The reaction mixture was allowed to stand in the dark at room temperature for 16-24 h before use and used within 2 days. The $\mathrm{ABTS}^{+}$solution was diluted with methanol to an absorbance of $0.700 \pm 0.050$ at $734 \mathrm{~nm}$. One hundred microliters of the diluted samples was mixed 
with $2.0 \mathrm{~mL}$ of diluted $\mathrm{ABTS}^{+}$solution. The mixture was allowed to stand for $6 \mathrm{~min}$ at room temperature and the absorbance was immediately recorded at $734 \mathrm{~nm}$. The scavenging rate and $\mathrm{EC}_{50}$ value were calculated using the equation described for DPPH assay. All extracts were tested in triplicates.

\subsubsection{Ferric Reducing Antioxidant Power (FRAP) Assay}

The reducing ability was determined by the method described by Xu et al. [30]. Briefly, the FRAP reagent was freshly prepared from $300 \mathrm{mM}$ sodium acetate buffer $(\mathrm{pH}$ 3.6), $10 \mathrm{mM}$ TPTZ solution in $40 \mathrm{mM} \mathrm{HCl}$ and $20 \mathrm{mM} \mathrm{FeCl}_{3}$ solution in proportions of 10:1:1 ( $/ \mathrm{v} / \mathrm{v})$, respectively. The FRAP reagent was prepared fresh daily and was warmed to $37{ }^{\circ} \mathrm{C}$ in a water bath prior to use. Then $0.1 \mathrm{~mL}$ of the tested sample solution was mixed with $1.8 \mathrm{~mL}$ of FRAP reagent and $3.1 \mathrm{~mL}$ ultra-pure water. The absorbance of the reaction mixture was measured at $593 \mathrm{~nm}$ after incubation for $30 \mathrm{~min}$ at $37{ }^{\circ} \mathrm{C}$. The standard curve was constructed using $\mathrm{FeSO}_{4}$ solution $(100-1000 \mu \mathrm{M})$, and FRAP value was expressed as micromoles Fe(II) per gram DW. All extracts were tested in triplicates.

\subsection{DNA Damage Protective Effect Assay}

The ability of samples to protect supercoiled pBR322 plasmid DNA against $\mathrm{H}_{2} \mathrm{O}_{2}$ was estimated by the DNA nicking assay as described by $\mathrm{Xu}$ et al. [30]. The reaction mixtures $(15 \mu \mathrm{L})$ contained $5 \mu \mathrm{L}$ of phosphate buffer saline (PBS, $10 \mathrm{mM}, \mathrm{pH} 7.4), 1 \mu \mathrm{L}$ of plasmid DNA $(0.5 \mu \mathrm{g}), 5 \mu \mathrm{L}$ of sample, $2 \mu \mathrm{L}$ of $1 \mathrm{mM} \mathrm{FeSO}_{4}$ and $2 \mu \mathrm{L}$ of $1 \mathrm{mM} \mathrm{H}_{2} \mathrm{O}_{2}$ were incubated at $37{ }^{\circ} \mathrm{C}$ for $30 \mathrm{~min}$. After incubation, $2 \mu \mathrm{L}$ of a loading buffer $(50 \%$ glycerol $(\mathrm{v} / \mathrm{v}), 40 \mathrm{mM}$ EDTA and $0.05 \%$ bromophenol blue) were added to stop the reaction and the reaction mixtures were electrophoresed on $1 \%$ agarose gel containing $0.5 \mu \mathrm{g} / \mathrm{mL}$ ethidium bromide in Tris/acetate/EDTA gel buffer for $60 \mathrm{~min}(60 \mathrm{~V})$, and the DNA in the gel was visualized and photographed under ultraviolet light. The protective effect were expressed as a percentage content of the supercoiled form of plasmid DNA treated with samples in untreated plasmid DNA. Trolox (100 $\mu \mathrm{M})$ was used as positive control.

\subsection{Statistical Analysis}

All experiments were conducted three times independently and the experimental data were expressed as mean \pm standard deviation (SD). One-way analysis of variance (ANOVA) and Duncan's multiple range tests were carried out to determine significant differences $(p<0.05)$ among the means by SPSS (version 13.0).

\section{Results and Discussion}

\subsection{Contents of Total Polyphenols}

The levels of total polyphenols in different extracts from Garcinia mangostana pericarp are shown in Fig. 1. Results showed that phenolic contents of different extracts varied considerably and ranged from 8.82 to $85.92 \mathrm{mg} \mathrm{GAE} / \mathrm{g}$ DW, respectively, for hexane and methanol. With respect to total phenolic content, solvents used in the present study could be classified in the following decreasing order: methanol $>$ acetone $>$ ethanol $>$ acetidin $>$ hexane. These results were basically consistent with previous studies [28, 29, 31]. However, unlike the present results, Cheok et al. [26] reported that the TPC of $245.78 \mathrm{mg} \mathrm{CGE} / \mathrm{g} \mathrm{DW}$ from mangosteen was obtained in ethanol, which may result from different extraction methods.

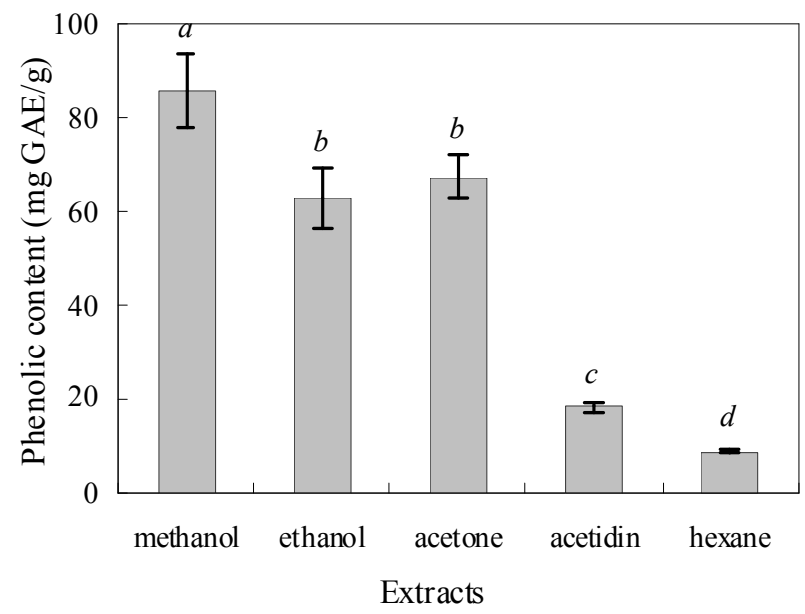

Figure 1. Total polyphenols content in different extracts. Data are expressed as the mean values of three independent replicates $\pm S D$. Different letters indicate statistically significant differences among the means $(P<0.05)$ for different extracts.

\subsection{DPPH Radical Scavenging Activity}

The antioxidant activity is influenced by many factors and there are more commonly used methods. The antioxidant activity cannot be fully described with one single method because of their advantages and disadvantages of each (43). Consequently, it is necessary to perform more than one type of antioxidant activity measurement to take into account the different mechanisms of antioxidant action. In this assay, the antioxidant activity of different extracts from Garcinia mangostana pericarp stages are measured by DPPH, ABTS and FRAP assays.

The effects of solvents on the DPPH scavenging activity of Garcinia mangostana pericarp extracts are shown in Table 1. The $\mathrm{EC}_{50}$ values of different extracts ranged from 60.5 (for methanol) to $154.7 \mu \mathrm{g} / \mathrm{mL}$ (for hexane). The methanol extract exhibited the highest scavenging activity on DPPH radicals, followed by acetone $\left(\mathrm{EC}_{50}=74.8 \mu \mathrm{g} / \mathrm{mL}\right)$, and ethanol $\left(\mathrm{EC}_{50}=75.9 \mu \mathrm{g} / \mathrm{mL}\right)$, the lowest for hexane extract $\left(\mathrm{EC}_{50}=154.7 \mu \mathrm{g} / \mathrm{mL}\right)$, but no significant difference was found between acetone and ethanol extracts.

\subsection{ABTS Cation Radical Scavenging Activity}

The profile of scavenging activity of different extracts from Garcinia mangostana pericarp on ABTS cation radicals was similar to the result of the scavenging activity 
on DPPH radicals (Table 1). Somewhat differently, the $\mathrm{EC}_{50}$ values on scavenging ABTS cation radicals ranged from 19.5 (for methanol) to $60.2 \mu \mathrm{g} / \mathrm{mL}$ (for hexane). With regard to ABTS radical scavenging activity, solvents could be sequenced in the following decreasing order: methanol $>$ acetone $>$ ethanol $>$ acetidin $>$ hexane, but there was no significant difference in scavenging activity among methanol, acetone and ethanol extracts. Similar to DPPH assay, ABTS cation radicals scavenging activity of different extracts increased dose-dependently at certain concentrations, which may be attributable to its hydrogen-donating ability thereby inhibiting the propagation of radical chain reactions.

Table 1. DPPH and ABTS radicals scavenging activity of different extracts from Garcinia mangostana pericarp

\begin{tabular}{llllll}
\hline & Extracts & Regression equation & $\mathbf{L r}^{a}(\boldsymbol{\mu g} / \mathbf{m L})$ & $\mathbf{R}^{2 \boldsymbol{b}}$ & $\mathbf{E C}_{\mathbf{5 0}}(\boldsymbol{\mu g} / \mathbf{m L})$ \\
\hline \multirow{4}{*}{ DPPH } & Methanol & $\mathrm{y}=0.6258 \mathrm{x}+12.11$ & $20-120$ & 0.9834 & $60.5 \pm 2.2 \mathrm{~d}$ \\
& Ethanol & $\mathrm{y}=0.5914 \mathrm{x}+5.12$ & $20-120$ & 0.9894 & $75.9 \pm 2.8 \mathrm{c}$ \\
& Acetone & $\mathrm{y}=0.5956 \mathrm{x}+5.45$ & $20-120$ & 0.9880 & $74.8 \pm 3.1 \mathrm{c}$ \\
& Acetidin & $\mathrm{y}=0.582 \mathrm{x}-10.30$ & $50-150$ & 0.9974 & $103.6 \pm 6.4 \mathrm{~b}$ \\
& Hexane & $\mathrm{y}=0.5104 \mathrm{x}-28.94$ & $100-200$ & 0.9999 & $154.7 \pm 5.5 \mathrm{a}$ \\
\multirow{4}{*}{ ABTS } & Methanol & $\mathrm{y}=39.54 \operatorname{Ln}(\mathrm{x})-67.45$ & $10-50$ & 0.9792 & $19.5 \pm 1.1 \mathrm{c}$ \\
& Ethanol & $\mathrm{y}=40.55 \operatorname{Ln}(\mathrm{x})-79.87$ & $10-50$ & 0.9866 & $24.6 \pm 2.7 \mathrm{c}$ \\
& Acetone & $\mathrm{y}=41.25 \operatorname{Ln}(\mathrm{x})-78.31$ & $10-50$ & 0.9634 & $22.4 \pm 3.4 \mathrm{c}$ \\
& Acetidin & $\mathrm{y}=31.38 \operatorname{Ln}(\mathrm{x})-70.52$ & $20-100$ & 0.9859 & $46.5 \pm 6.2 \mathrm{~b}$ \\
\hline
\end{tabular}

Values are represented as mean \pm standard deviation of triplicates; Different letters within a column indicate statistically significant differences among the means at $\mathrm{P}<0.05 .{ }^{\mathrm{a}}$ Linearity range. ${ }^{\mathrm{b}}$ Determination coefficient values.

\subsection{Ferric Reducing Antioxidant Power (FRAP)}

Fig. 2 showed that different extracts of pericarp of Garcinia mangostana exhibited different reducing power. The reducing power of extracts ranged from 0.13 to 0.81 $\mathrm{mmol} \mathrm{Fe}(\mathrm{II}) / \mathrm{g} \mathrm{DW}$, and were found to be in the following order: methanol $>$ acetone $>$ ethanol $>$ acetidin $>$ hexane, as observed in the DPPH and ABTS radical scavenging capacities measurements. The result suggested that extracts of Garcinia mangostana pericarp had a remarkable potency to donate electron to reactive free radicals, converting them into more stable non-reactive species and terminating the free radical chain reaction.

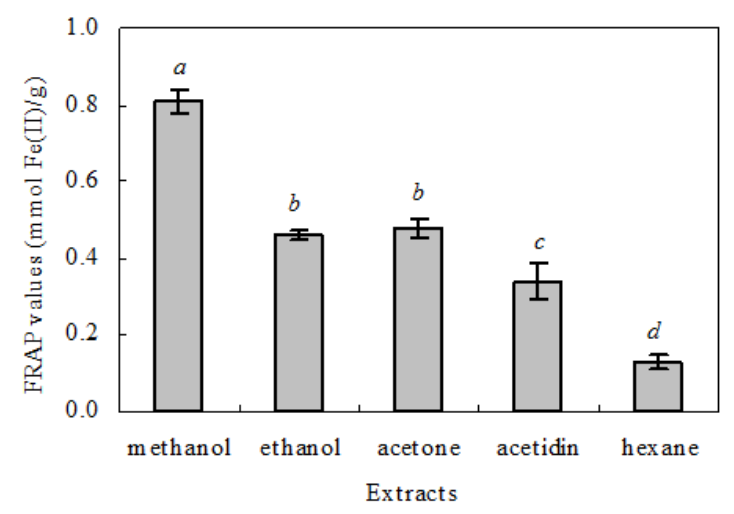

Figure 2. Reducing power of different extracts. Data are expressed as the mean values of three independent replicates $\pm S D$. Different letters indicate statistically significant differences among the means $(P<0.05)$ for different extracts.

\subsection{DNA Damage Protective Effect}

The effect of different extracts of Garcinia mangostana pericarp in preventing oxidative damage of DNA induced by $\mathrm{H}_{2} \mathrm{O}_{2}$ was also evaluated and the result (concentration of each sample at $100 \mu \mathrm{g} / \mathrm{mL}$ ) is shown in Fig. 3.

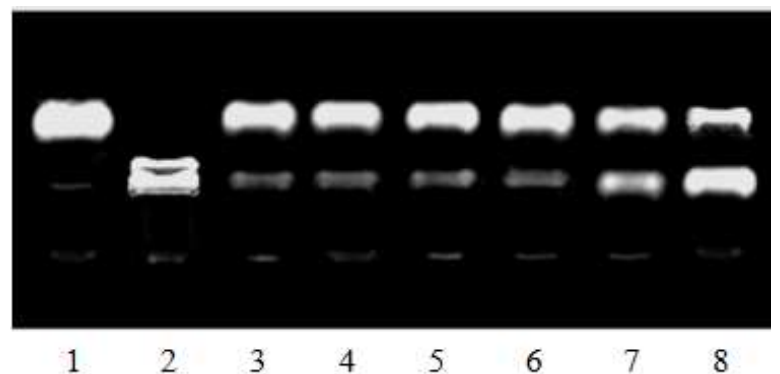

Figure 3. DNA damage protective effect of different extracts from Garcinia mangostana pericarp. Lane 1, native DNA; Lane 2, DNA treated with $1 \mathrm{mM} \mathrm{FeSO}_{4}$ and $1 \mathrm{mM} \mathrm{H}_{2} \mathrm{O}_{2}$; Lane 3, DNA treated with Trolox (100 $\mu \mathrm{M}), 1 \mathrm{mM} \mathrm{FeSO}_{4}$ and $1 \mathrm{mM} \mathrm{H} \mathrm{O}_{2}$; Lane 4-8, DNA treated with $1 \mathrm{mM}$ $\mathrm{FeSO}_{4}$ and $1 \mathrm{mM} \mathrm{H} \mathrm{H}_{2} \mathrm{O}_{2}$, and treated with methanol, ethanol, acetone, acetidin, and hexane, respectively.

The plasmid DNA was mainly of the supercoiled form (Fig. 3, Lane 1). During the addition of $\mathrm{Fe}^{2+}$ and $\mathrm{H}_{2} \mathrm{O}_{2}$, the supercoiled form of DNA converted into the open circular and linear forms (Fig. 3, Lane 2) indicating that hydroxy radicals generated from iron-mediated decomposition of $\mathrm{H}_{2} \mathrm{O}_{2}$ produced both single-strand and double-strand DNA breaks. From the gel analysis, the DNA damage protective effect measured in different samples ranged from $24.8 \%$ to $82.5 \%$, and the order was methanol $\geq$ acetone $\geq$ ethanol $>$ acetidin $>$ hexane. The protective effect of methanol, acetone, and ethanol extracts is approximately the same as compared to that of $100 \mu \mathrm{M}$ of Trolox, which indicated they probably quenched hydroxy radicals by donating hydrogen-atom or electron, and therefore protecting the supercoiled plasmid DNA from hydroxy radicals dependent strand breaks [30]. 
To further investigate their relationship, the correlation among the content of total polyphenols and bioactivities of different extracts was established. In this study, the content of total polyphenols was highly correlated to the antioxidant activities ( $\mathrm{R} \geq 0.9112)$, and was moderately correlated to the DNA damage protective effect of extracts $(\mathrm{R}=0.7552)$, indicating total polyphenols are the main constituents contributing to the bioactivities of extracts from Garcinia mangostana pericarp, which was supported by previous reports studied on other plants [7, 27]. On the basis of these results, it is possible to conclude that Garcinia mangostana pericarp is a kind of food resources with some high healthy functions, but total polyphenols of extracts were significantly affected by the extracting solvents, which results in variation of the bioactivities.

\section{Conclusion}

The extracting solvents significantly affected the content of total polyphenols, antioxidant activities as well as DNA damage protective effect of Garcinia mangostana pericarp. In our study, methanol, acetone, and ethanol extracts exhibited the better protective effect. The methanol extract from Garcinia mangostana pericarp possessed the highest content of total polyphenols and the strongest antioxidant activity. The acetone and ethanol extracts had the higher content of total polyphenols and also exhibited higher antioxidant activities, while other extracts had both lower the content of active compounds and bioactivities. These results indicated that selective extraction from natural sources, by an appropriate solvent, is important for obtaining fractions with high antioxidant activity.

\section{Acknowledgements}

This work was financially supported by a project of the Natural Science Foundation of Shanxi Province, China (project no. 2012011031-3), and a Program for the Top Young Academic Leaders of Higher Learning Institutions of Shanxi.

\section{References}

[1] Bidchol, A.M., Wilfred, A., Abhijna, P., Harish, R. (2011) Free radical scavenging activity of aqueous and ethanolic extract of Brassica oleracea L. var. italic. Food Bioprocess Technol. 4:1137-1143.

[2] Alexandrova, M. L., Bochev, P. G. (2005). Oxidative stress during the chronic phase after stroke. Free Radical Biol. Med. 39: $297-316$.

[3] Jayaprakasha, G. K., Selvi, T., Sakariah, K. K. (2003). Antibacterial and antioxidant activities of grape (Vitis vinifera) seed extracts. Food Res. Int. 36: 117-122.

[4] Sokmen, A., Gulluce, M., Akpulat, H. A., Daferera, D., Tepe, B., Polissiou, M., Sokmen, M., Sahin, F. (2004). The in vitro antimicrobial and antioxidant activities of the essential oils and methanol extracts of endemic Thymus spathulifolius. Food Control. 15: 627-634.

[5] Shan, B., Cai, Y. Z., Brooks, J. D., Corke, H. (2007). Antibacterial properties and major bioactive components of cinnamon stick (Cinnamomum burmannii): activity against foodborne pathogenic bacteria. J. Agric. Food Chem. 55: $5484-5490$.

[6] Tiwari, B. K., Valdramidis, V. P., Donnel, C. P. O., Muthukumarappan, K., Bourke, P., Cullen, P. J. (2009). Application of natural antimicrobials for food preservation. J. Agric. Food Chem. 57: 5987-6000.

[7] Delgado-Adámez, J., Fernández-León, M. F., Velardo-Micharet, B., González-Gómez, D. (2012). In vitro assays of the antibacterial and antioxidant activity of aqueous leaf extracts from different Prunus salicina Lindl. cultivars. Food Chem. Toxicol. 50: 2481-2486.

[8] Voon, H. C., Bhat, R., Gulam, R. (2012). Flower extracts and their essential oils as potential antimicrobial agents. Compr. Rev. Food Sci. F. 11: 34-55.

[9] Burt, S. (2004). Essential oils: their antibacterial properties and potential applications in foods-a review. Int. J. Food Microbiol. 94: 223-253.

[10] Rymbai, H., Sharma, R. R., Srivasta, M. (2011). Bio-colorants and its implications in health and food industry-a review. Int. J. Pharma Res. 3: 2228-2244.

[11] Pedraza-Chaverri, J., Cárdenas-Rodríguez, N., OrozocoIbarra, M., Pérez-Rojas, J. M. (2008). Medicinal properties of mangosteen (Garcinia mangostana). Food Chem. Toxicol. 46: 3227-3239.

[12] Jung, H. A., Su, B. N., Keller, W. J., Mehta, R. G., Kinghorn, D. (2006). Antioxidant xanthones from pericarp of Garcinia mangostana (Mangosteen). J. Agric. Food Chem. 54: 2077-2082.

[13] Suksamrarn, S., Komutib, O., Ratananukul, P., Chimnol, N., Lartpornmatulee, N., Sukamrarn, A. (2006). Cytotoxic prenylated xanthones from the young fruit of Garcinia mangostana. Chem. Pharm. Bull. 54: 301-305.

[14] Obolskiy, D., Pischel, I., Siriwatanametanon, N., Heinrich, M. (2009). Garcinia mangostana L.: A phytochemical and pharmacological review. Phytother Res. 23: 1047-1065.

[15] Mahabusarakam, W., Wiriyachitra, P. (1987). Chemical constituents of Garcinia mangostana. J. Nat. Prod. 50: 474-478.

[16] Zadernowski, R., Czaplicki, S., Naczk, M. (2009). Phenolic acid profiles of mangosteen fruits (Garcinia mangostana). Food Chem. 112: 685-689.

[17] Wittenauer, J., Falk, S., Schweiggert-Weisz, U., Carle, R. (2012). Characterisation and quantification of xanthones from the aril and pericarp of mangosteens (Garcinia mangostana L.) and a mangosteen containing functional beverage by HPLC-DAD-MS ${ }^{\mathrm{n}}$. Food Chem. 134: 445-452.

[18] Jung, H. A., Su, B. N., Keller, W. J., Mehta, R. G., Kinghorn, A. D. (2006). Antioxidant xanthones from the pericarp of Garcinia mangostana (mangosteen). J. Agric. Food Chem. 54: 2077-20852. 
[19] Yu, L., Zhao, M., Yang, B., Zhao, Q., Jiang, Y. (2007). Phenolics from hull of Garcinia mangostana fruit and their antioxidant activities. Food Chem. 104: 176-181.

[20] Sakagami, Y., Iinuma, M., Piyasena, K. G. N. P., Dharmaratne, H. R. W. (2005). Antibacterial activity of $\alpha$-mangostin against vancomycin resistant Enterococci (VRE) and synergism with antibiotics. Phytomedicine, 12: 203-208.

[21] Chomnawang, M. T., Sakagami, S. S., Nukoolkarn, V. S., Gritsanapan, W. (2005). Antimicrobial effects of Thai medicinal plants against acne-inducing bacteria. J. Ethnopharmacol. 101: 330-333.

[22] Chen, L. G., Yang, L. L., Wang, C. C. (2008). Anti-inflammatory activity of mangostins from Garcinia mangostana. Food Chem. Toxicol. 46: 688-693.

[23] Yu, L., Zhao, M., Yang, B., Bai, W. (2009). Immunomodulatory and anticancer activities of phenolics from Garcinia mangostana fruit pericarp. Food Chem. 116: 969-973.

[24] Cui, J., Hu, W., Cai, Z., Liu, Y., Li, S., Tao, W., Xiang, H. (2010). New medicinal properties of mangostins: Analgesic activity and pharmacological characterization of active ingredients from the fruit hull of Garcinia mangostana L. Pharmacol, Biochem. Be. 95: 166-172.

[25] Aspé, E., Fernández, K. (2011). The effect of different extraction techniques on extraction yield, total phenolic, and antiradical capacity of extracts from Pinus radiate bark. Ind. Crops Prod. 34: 838-844.
[26] Cheok, C. Y., Chin, N. L., Yusof, Y. A., Talib, R. A., Law, C. L. (2013). Optimization of total monomeric anthocyanin (TMA) and totalphenolic content (TPC) extractions from mangosteen (Garcinia mangostana Linn.) hull using ultrasonic treatments. Ind. Crops Prod. 50: 1-7.

[27] Alothman, M., Bhat, R., Karim, A. A. (2009). Antioxidant capacity and phenolic content of selected tropical fruits from Malaysia, extracted with different solvents. Food Chem. 115: 785-788.

[28] Cheok, C. Y., Chin, N. L., Yusof, Y. A., Law, C. L. (2012). Extraction of total phenolic content from Garcinia mangostana Linn. hull. I. Effects of solvents and UV-Vis spectrophotometer absorbance method. Food Bioprocess Technol. 5: 2928-2933.

[29] Rebey, I. B., Bourgou, S., Debez, I. B. S., Karoui, I. J., Sellami, I. H., Msaada, K., Limam, F., Marzouk, B. (2012). Effects of extraction solvents and provenances on phenolic contents and antioxidant activities of cumin (Cuminum cyminum L.) seeds. Food Bioprocess Technol. 5: 2827-2836.

[30] Xu, J. G., Hu, Q. P., Liu, Y. (2012). Antioxidant and DNA-protective activities of chlorogenic acid isomers. J. Agric. Food Chem. 60: 11625-11630.

[31] Turkmen, N., Sari, F., Sedat Velioglu, Y. (2006). Effects of extraction solvents on concentration and antioxidant activity of black and black mate tea polyphenols determined by ferrous tartrate and Folin-Ciocalteu methods. Food Chem. 99: 835-841. 